\title{
Sudden Unexpected Postnatal Collapse of Newborn Infants: A Review of Cases, Definitions, Risks, and Preventive Measures
}

\author{
Eric Herlenius • Pierre Kuhn
}

Received: 13 November 2012 /Revised: 31 January 2013 / Accepted: 4 February 2013 / Published online: 23 February 2013

(C) The Author(s) 2013. This article is published with open access at Springerlink.com

\begin{abstract}
This study aimed to review available published reports concerning sudden unexpected postnatal collapse (SUPC) of apparently healthy infants within the first days of postnatal life, establish a structured presentation and delineate recommendations for preventive measures. All published reports of SUPC cases were retrospectively analyzed, and three not previously published SUPC cases at Karolinska University Hospital were detailed to exemplify the varying presentations and outcomes of SUPC. We found 398 published cases of SUPC occurring during first postnatal week. Estimated incidence of the SUPC of a presumably healthy infant after birth differs widely, ranging from 2.6 cases to 133 cases $/ 100,000$. However, definition, inclusion, and exclusion criteria vary substantially between reports. Our summary indicates that reported SUPC occurs more frequently than expected from recent surveys. About half of the infants die, and of the remaining survivors, half have neurological sequela. Of the 233 cases of sudden unexpected
\end{abstract}

Sudden unexpected postnatal collapse (SUPC) of healthy infants within the first days after birth is a rare event but consequences are often catastrophic. Sudden apparent life-threatening events and deaths may occur during the first postnatal week and happens more frequently than indicated in recent national surveys limited to events within the first $24 \mathrm{~h}$. Three new SUPC cases are described to illustrate the varying presentation, outcome as well as possible etiologies and testable hypothesizes. Healthy newborns, especially during skin-to-skin contact in prone position, should be supervised during the first hours of postnatal life without interfering with the mother-child bonding to prevent SUPC.

E. Herlenius $(\varangle) \cdot$ P. Kuhn

Neonatal Unit Q2:07, Department of Women's and Children's

Health, Astrid Lindgren Children's Hospital, Karolinska Institutet,

17176 Stockholm, Sweden

e-mail: eric.herlenius@ki.se

P. Kuhn

Service de Pediatrie 2, Médecine et Réanimation néonatales, Hopital de Hautepierre, Centre Hospitalier Universitaire de

Strasbourg, Strasbourg, France death described, no etiology was found in 153 cases. When a defined time for the SUPC event is described, approximately one third of reported events occur during the first $2 \mathrm{~h}$, between 2 and $24 \mathrm{~h}$ and between 1 and 7 days after birth, respectively. Adequate education of caregivers and appropriate surveillance during the first days of newborns should enable us to save hundreds of lives.

Keywords Sudden unexpected postnatal collapse $\cdot$ Prone Hypoxia $\cdot$ Birth asphyxia $\cdot$ Adenosine $\cdot$ Prostaglandin . Cardiorespiratory control

$\begin{array}{ll}\text { Abbreviations } \\ \text { SUPC } & \text { Sudden unexpected postnatal collapse } \\ \text { eSIDS } & \text { Early sudden infant death syndrome } \\ \text { ALTE } & \text { Apparent life threatening event } \\ \text { SUDI } & \text { Sudden unexpected death in infancy } \\ \text { SUEND } & \text { Sudden unexpected early neonatal death } \\ \text { BE } & \text { Base excess } \\ \text { EEG } & \text { Electroencephalography } \\ \text { CPAP } & \text { Continuous positive airway pressure } \\ \text { HIE } & \text { Hypoxic ischemic encephalopathy } \\ \text { TTN } & \text { Transient tachypnea of the newborn } \\ \text { PFO } & \text { Patent foramen ovale } \\ \text { ICD } & \text { International Classification of Disease } \\ \text { PDA } & \text { Patent ductus arteriosus } \\ \text { PGE } 2 & \text { Prostaglandin E2 } \\ \text { mPGES-1 } & \text { Microsomal prostaglandin E synthase-1 } \\ \text { SSC } & \text { Safe early skin-to-skin care }\end{array}$

\section{Introduction}

Sudden unexpected postnatal collapse (SUPC) of apparently healthy term or near-term infants within the first days of life is rare but can have catastrophic consequences. About $5 \%$ 
of unexpected infant deaths during the first year of life occur during the first postnatal week [1].

SUPC includes both severe apparent life-threatening event (ALTE) and sudden unexpected death in infancy (SUDI) occurring within the first postnatal week. Sudden unexpected early neonatal death (SUEND) in the first week of life shares features with SUDI but is not included as SUDI, which is limited to postperinatal deaths (1 week1 year). As SUPC is unexpected, infants with well-known risk factors, e.g., prematurity ( $<35$ week gestation), perinatal asphyxia, or congenital malformations are not included in published reports as they are classified as "expected" neonatal deaths or ALTE events [1].

Even if considered rare, consequences are serious with death in half of the cases and remaining disability in a majority of the cases reported [2-4]. Polberger and Svenningsen [5] described, in a regional and a populationbased study, sudden cardiovascular collapse, occurring between 6 and $100 \mathrm{~h}$ after birth, in infants considered healthy at birth. Here, the incidence of early neonatal sudden unexpected death and severe early-ALTE was established as 12 and 35 cases per 100,000 live births, respectively [5].

Recent national surveys from the UK and Germany have used different criteria for inclusion; SUPC is defined as occurring within the first 24 postnatal hours and excluding (Germany) respectively including (UK) identified and possibly preventable causes $[3,6]$. Both these national surveys report an incidence of about 3 cases/100,000 infants. However, recently published guidelines for investigations of SUPC include infants with sudden unexpected collapse during the first week of life [7]. These "Guidelines for the investigations of newborn infants who suffer a sudden and unexpected postnatal collapse in the first week of life" mentions 14 published reports concerning SUPC [7]. However, not all publications concerning SUPC are included; neither have a summary of existing SUPC reports and their respective definition of and inclusion criteria for SUPC been done or published.

Thus, we performed an exhaustive literature review of SUPC cases to do a structured presentation of definitions, inclusions, gestational age, and postnatal time of occurrence in published cases. We also describe new cases of SUPC to illustrate and highlight some varying presentations and outcomes. Finally, in view of all the presented data, we summarize preventive measures that might save hundreds of lives.

\section{Methods}

Scopus, Web of Science, and Medline databases were searched to retrieve and analyze published SUPC cases and reports concerning early SUDI, early neonatal sudden unexpected death, SUEND, and early ALTE occurring during the first postnatal days in presumably healthy term and near term newborns. The selection criteria of the published articles were derived from the general guidelines for systematic reviews [8, 9]. All the terms comprised in "SUPC," "SUDI," "SUEND," "ALTE," and the terms "newborn infant" or "neonate" were used as MesH terms for the research process. All references of retrieved articles were cross-searched.

We used the recent definition of a SUPC event established in "The guidelines for the investigation of newborn infants who suffer a sudden and unexpected postnatal collapse" [7]. We thus included infants born $>35$ weeks gestational age, with 10 min Apgar of $>7$, considered healthy who collapsed suddenly and unexpectedly within the first postnatal week $[7,10,11]$.

We excluded cases that occurred after the first week of life and only retained articles in which minimal neonatal data were available. All articles with an English language title were analyzed. Non-English articles in French or Spanish were analyzed with the help of native language scientist in the research group (Drs. Kuhn and Perez, respectively). Unpublished studies were excluded.

We then determined which type of study (case report, site, regional study, or population survey) and which inclusion and exclusion criteria (gestational age, postnatal age, underlying conditions, outcome, as well as risk and associated factors) were reported. All cases including those where a possible etiology to the SUPC event was found during autopsy or after clinical investigations in survivors were eligible. Inquiries regarding inclusion and exclusion criteria were addressed to Drs. Christian and Anette Poets regarding the two German national inquiries [3, 12].

In order to illustrate the varying presentations and outcomes of this condition, an examination of three cases of SUPC occurring in presumably healthy newborns at the Karolinska University Hospital-Solna, Stockholm, Sweden, not previously reported, was performed. Characteristics of mothers and infants perinatal, postpartum, events and subsequent investigations, and outcome data at discharge and at 1 year of age follow-up were recorded and analyzed.

The study was performed in accordance with European Community guidelines and approved by the regional hospital research ethics committee.

\section{Results}

Review of Published Cases

We found 400 published cases of SUPC occurring during first postnatal week. Two cases were excluded due to insufficient neonatal data available. These 2 cases were described in two articles investigating possible pathologies of SUDI. One article refers only to one case of a female newborn where SUPC occurred at 2 days of life, in a cohort of infants in whom an 
anomaly of the pulmonary artery was found [13]. The other excluded article retrospectively reviews autopsies of neonatal SUDI cases occurring before 28 days of life, to look for brain lesions, and reports only one case of death that occurred in the first week of life, when "the infant was still in the neonatal ward," but with no other perinatal information described [14]. Tables 1 and 2 give an overview of the remaining 398 cases of SUPC reported in 26 different studies. Table 1 lists reports that have early neonatal sudden unexpected deaths as inclusion criteria, and Table 2 lists SUPC studies where both SUDI/SUEND and ALTE during initial hours to days of life are included.

Most publications are case reports, but regional cohorts as well as national surveys exist. Estimated incidence of SUPC vary between 1.6 to $133 / 100,000$ live born infants, excluding congenital malformations and preterm infants born before gestational week $35(<38)$. However, interpretations must be made with caution as the inclusion criteria differ widely. Some studies only include SIDS, unexplained deaths occurring $<2 \mathrm{~h}$ [15-17], while other reports include early-unexpected ALTE events during first week of life also when a plausible etiology is found after postevent investigations $[18,19]$.

We have summarized in Table 3 the reports where time of SUPC event is described. A third of reported cases occur during the first two hours of life $(n=106,33 \%)$. This summary is biased, as different postnatal age exclusion criteria have been used. For example, only 8 out of 26 studies included cases occurring between the third and seventh postnatal day. Nonetheless, Table 3 gives a systematic overview of the different cases, studies, and postnatal age exclusion criteria used. Notably, among the 11 studies that include SUPC occurring within $72 \mathrm{~h}$ of postnatal age, about half of SUPC cases occur $<24 \mathrm{~h}$ and between $24-72 \mathrm{~h}$ postnatal age respectively [ 84 and 73 cases out of 157 SUPC reported, in these studies (54 and $46 \%$ )].

\section{Illustrative Cases}

Three different cases of SUPC are described with varying presentations and outcomes. All three events occurred during skin-to-skin contact in prone position.

Case 1 A boy born at gestational age 41 weeks, 3,683 g, cardiotocogram variable decelerations and thin meconium present during last minutes of, an otherwise uneventful, vaginal delivery. He was hypotonic at $1 \mathrm{~min}$ age, Apgar score 7, but rapidly recovered with rosy color good responsiveness and breathing movements with Apgar score 9 at $5 \mathrm{~min}$ and 10 at $10 \mathrm{~min}$. Due to umbilical cord artery $\mathrm{pH} 7.0$, base excess (BE)-15 (mmol/L), and metabolic acidosis, he received a bolus dose of Tribonate ${ }^{\circledR} 15 \mathrm{~mL}$ and $10 \%$ glucose $5 \mathrm{~mL}$ and supplemental oxygen during initial
$15 \mathrm{~min}$. At $20 \mathrm{~min}$, he was alert, responsive with good saturation, also without supplemental oxygen. He was presumed to be healthy and placed prone on the mother's chest for skin-to-skin contact. He was seen, still in prone position, and considered healthy by midwife as well as pediatrician at $80 \mathrm{~min}$ postnatal age, 2130 hours in the evening. At $100 \mathrm{~min}$ (2150 hours), he was discovered cyanotic, hypotonic, without breathing movements or pulse by midwife. Immediate and extensive resuscitation commenced including cardiac compression and intubation. Blood gas minutes after event revealed $\mathrm{pH} 6.71, \mathrm{pCO}_{2}$ of $15, \mathrm{pO}_{2}$ of 11 , and $\mathrm{BE}$ of -21 $(\mathrm{mmol} / \mathrm{L})$. Adrenaline injection and Tribonate ${ }^{\circledR}$ boluses were given, and after $7 \mathrm{~min}$, he had $>100$ heartbeats/minute and subsequently normalized oxygen saturation and blood gases. He was placed on mechanical ventilation after $30 \mathrm{~min}$ of resuscitation due to absence of spontaneous breathing movements. Generalized seizures begun at $180 \mathrm{~min}$ postnatal age and were stabilized with phenobarbital. Brain cerebral function monitoring exhibited burst suppression pattern. Lumbar puncture performed $18 \mathrm{~h}$ after collapse revealed clear cerebrospinal fluid. Due to isoelectric EEG and hypoxic-ischemic encephalopathy (HIE) grade III, he was detached from mechanical ventilation after parental consent and subsequently died at $23 \mathrm{~h}$ of age. Extended investigations including autopsy did not reveal any malformations, infections, or sign of prenatal events that could explain the sudden collapse and early death of this infant, an early SIDS.

Case 2 A girl born at gestational age 40 weeks and 5 days, $3,455 \mathrm{~g}$ by normal primiparous vaginal delivery. Her Apgar scores were 9,10 , and 10 at 1,5 , and $10 \mathrm{~min}$ of age, with normal adequate postnatal examinations and behavior. She started breastfeeding under midwife supervision. She was hungry, and supplemental milk was given with two normal blood glucose controls $<23 \mathrm{~h}$ postnatal age. At $24 \mathrm{~h}$ postnatal age, 1330 hours in the afternoon, while in prone breastfeeding position, the mother discovered her daughter motionless, cyanotic without breathing movements. Immediate resuscitation with vigorous stimulation led to rapid, within minute, recovery of spontaneous breathing and normal color and tonus and responsiveness after some two to three additional minutes. A full investigation for possible sepsis was performed, including blood, urine, and cerebrospinal fluid (CSF) cultures. All results were negative including brain ultrasound. After $24 \mathrm{~h}$ extra surveillance at the neonatal intensive care unit and four-dose antibiotic treatment, until blood and CSF cultures were negative, the girl was considered healthy. Follow-up and outcome were normal.

Case 3 A boy, first twin, born at gestational age week 36 and 3 days. He was delivered after a planned cesarean 


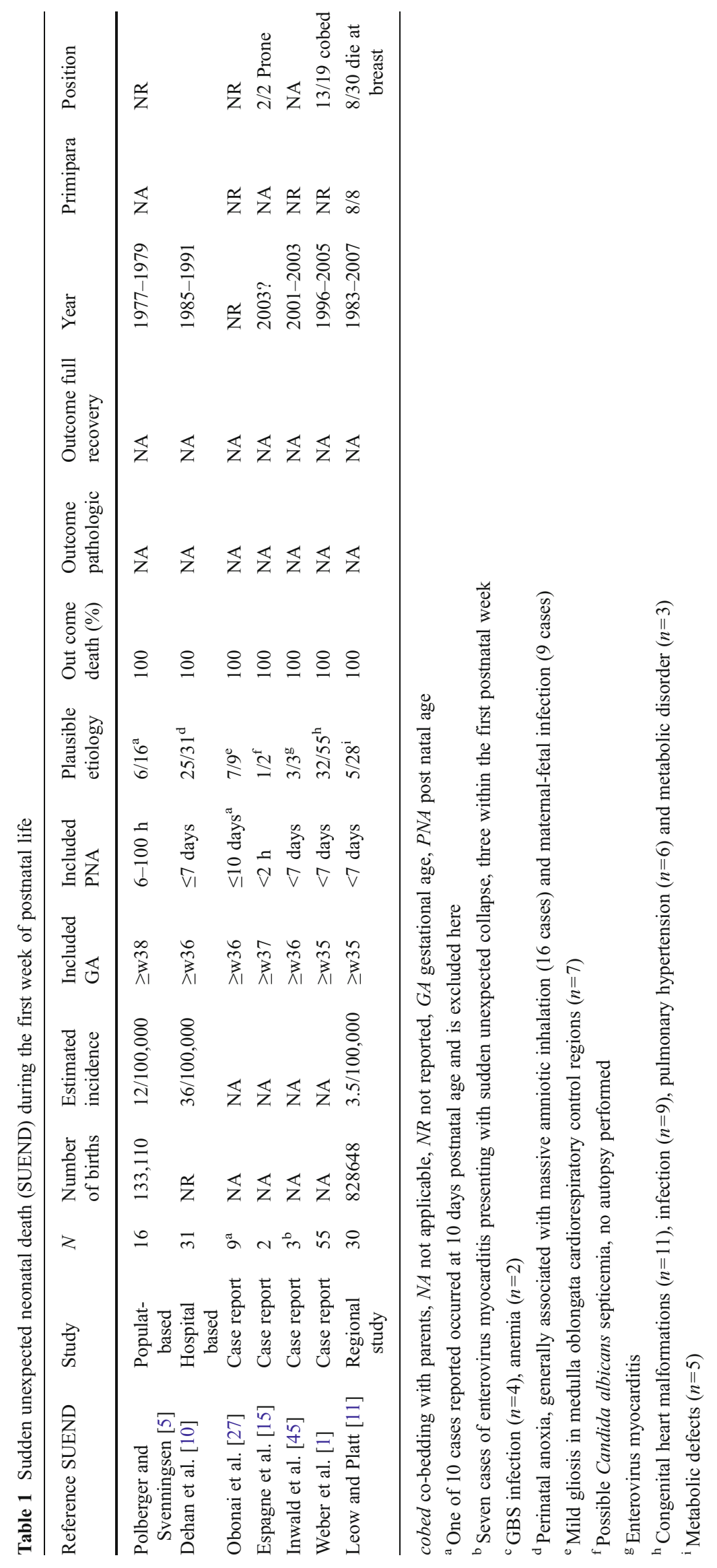




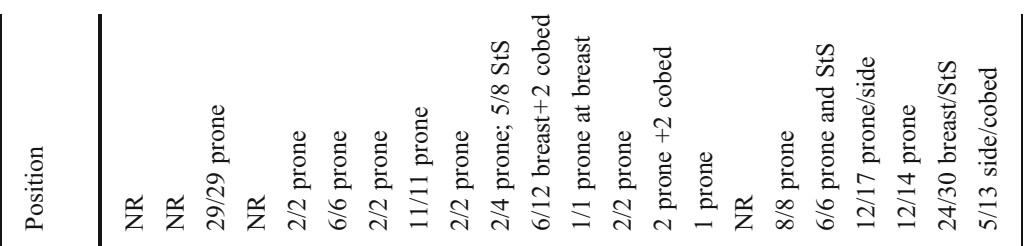

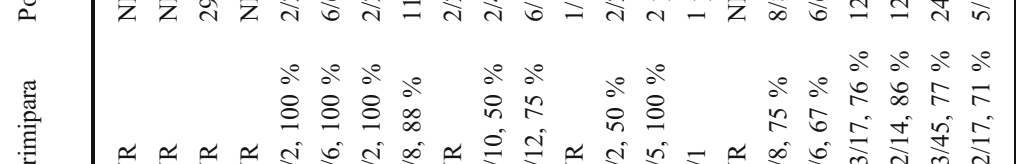

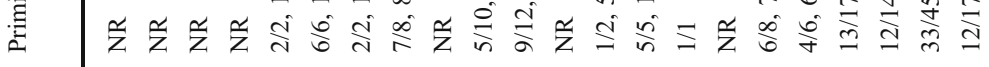

范 Б大

丞

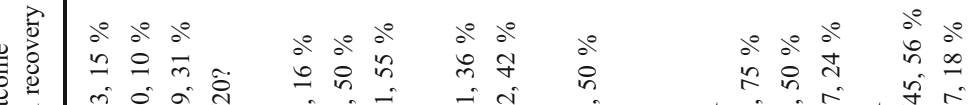

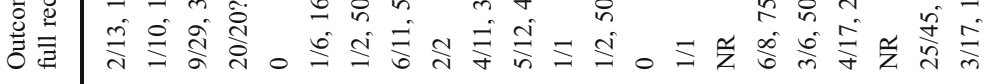

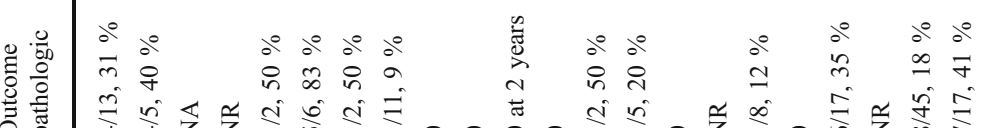

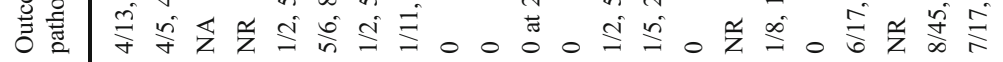

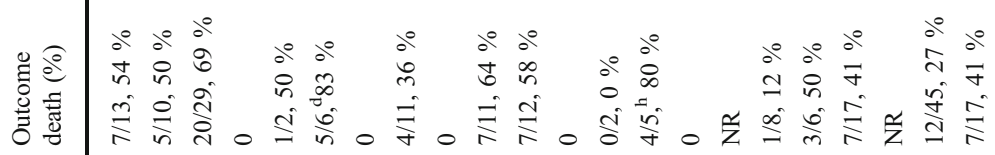

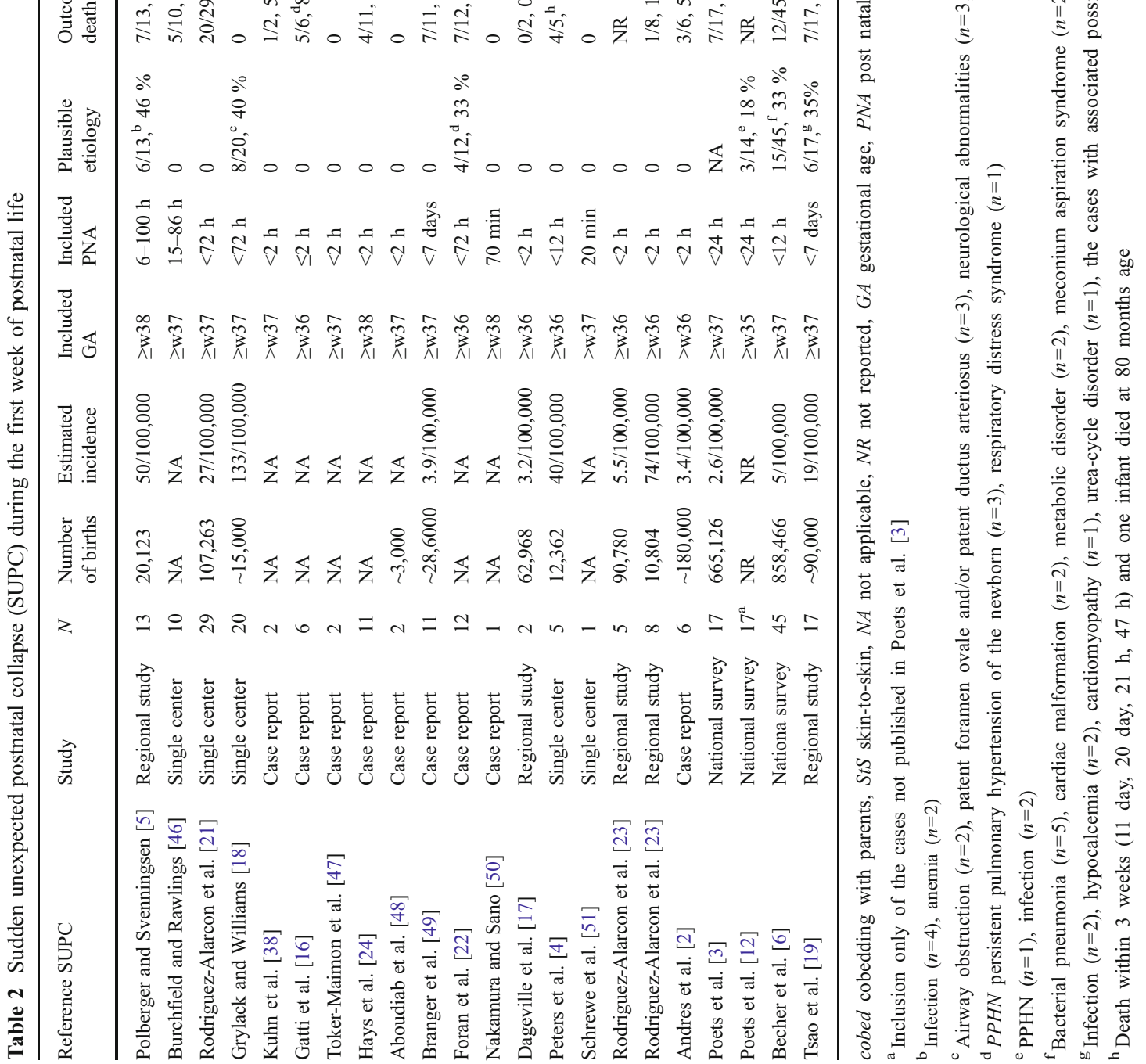


section that was performed due to a risk for preeclampsia development in a primiparous mother and because both twins were in breech position. A proportional healthy boy, $2.48 \mathrm{~kg}$ and $49 \mathrm{~cm}$ length was delivered with Apgar 9, 10, and 10 at 1, 5 , and $10 \mathrm{~min}$ of age and umbilical cord artery $\mathrm{pH} 7.3$, and $\mathrm{BE}$ of $-2(\mathrm{mmol} / \mathrm{L})$. He exhibited good sucking reflexes and started breastfeeding immediately and had normal bloodglucose levels and normal postnatal weight loss during first day. Due to tachypnea (60-72 breaths/min) and saturation levels between 80 and $90 \%$, he received supplementary $\mathrm{O}_{2}$ $(30 \%)$ via continuous positive airway pressure (CPAP). Several pediatric checkups were made during the first $24 \mathrm{~h}$ with normal CRP level $(<\mathrm{mg} / \mathrm{L})$ and clinical status except a breathing frequency around $60-70 / \mathrm{min}$. Due to tachypnea, infectious workup and lung X-ray were performed, and he was diagnosed as having a mild transient tachypnea of the newborn (TTN). At $35 \mathrm{~h}$ postnatal age, (2330 hours at night), the midwife saw him breastfeeding in prone position. The midwife then noted that he suddenly became pale, hypotonic, and apneic. Bag and mask resuscitation were initiated, and cardiac compression commenced as no pulse could be detected. After $2 \mathrm{~min}$, he remained apneic, pale and unresponsive, and had bradycardia (about 100 beats $/ \mathrm{min}$ ). Blood-gas showed $\mathrm{pH}$ 6.98 and $\mathrm{BE}$ of $-15(\mathrm{mmol} / \mathrm{L})$, and he received $\mathrm{NaCl}$-bolus $(10 \mathrm{~mL} / \mathrm{kg})$, Tribonate ${ }^{\circledR} 8 \mathrm{~mL}$, and supplementary oxygen. Some minutes later, gasping began. Subsequently, he commenced breathing with normal saturation under supplementary oxygen, but had an elevated lactate $(10 \mathrm{mmol} / \mathrm{L})$. As he was still pale with decreased peripheral circulation, blood culture, infection samples were taken before intravenous antibiotics with ongoing surveillance at the neonatal intensive care unit. Infectious and metabolic investigations were all normal.

Echocardiography revealed an atrial-septal defect $(7 \mathrm{~mm})$ and a patent ductus arteriosus (PDA, $3 \mathrm{~mm}$ ) at $48 \mathrm{~h}$ postnatal age. PDA remained until day 4 before spontaneously closing during the subsequent days. He received CPAP with air until $60 \mathrm{~h}$ postnatal age, discontinued with adequate blood saturation levels. He was irritable, and brain ultrasound at days 2 and 3 revealed an HIE grade 1. No seizures and normal electroencephalogram. The persistent foramen ovale (PFO) diminished from 7 to $3-4 \mathrm{~mm}$ during a week and was not present at 5-month follow-up. During cardiovascular recordings and tilt test [20], he exhibited an immature but not pathological cardiovascular response. His twin brother also had a similar, but less pronounced, immature cardiovascular response. This immature response remained at examination at 3 and 7 months but was normal at 12-month follow-up. Normal neuromotor development and no sequela were detected at 12-month follow-up. Cases 1 and 2 occurred 2001 and case 3 in 2010. These cases illustrate the varying outcome and presentation of SUPC that occurs in the delivery wards and in the available literature. However, a systematic review of all the SUPC events reported during 2001 until 2010 at the Karolinska University hospitals has not yet been performed.

\section{Discussion}

Based on our exhaustive review of previous published case reports, regional studies, and national surveys of SUPC, several questions emerge and can be addressed. When discussing them, we will use data coming from our three described cases that illustrate the broad spectrum of SUPC: case 1, SUDI-early SIDS $<2 \mathrm{~h}$ postnatal age; case 2 , ALTE at $24 \mathrm{~h}$ postnatal age, with good outcome and no etiology found; and finally, case 3, an ALTE event during second postnatal day with possible etiologies, TTN, persistent foramen ovale, and immature cardiorespiratory control. All occurred unexpectedly during skinto-skin contact in prone position.

\section{How Often Do SUPC in Healthy Newborns Occur?}

Reports have used varying inclusion and exclusion criteria for SUPC requiring caution when comparing estimations of incidence. The definitions of when (gestational age $>$ week 35 or $>$ week 38$)$ and onset of $(<2,<12,<24,<72 \mathrm{~h}$ or within 7 days after birth) unexpected collapses of apparent healthy infants occur differ between published reports, i.e. [2, 3, 6, 12, 21, 22] (Table 1). Single center reports an incidence of 27-40 SUPC cases per 100,000 births, but inclusion have been $<12$ and $<72 \mathrm{~h}$ postnatal age, respectively [4, 21]. Several case reports from French maternity wards exist, and two estimate incidence to be 3.2-3.6/100,000 [2, 17]. Reports from Spain describe an incidence between 5.5 and 74/100,000 [21, 23]. However, these French and Spanish studies have only included cases occurring within $2 \mathrm{~h}$ after birth [2, 16, 17, 23, 24]. Recent national surveys from the UK and Germany have used yet another time criteria for inclusion; SUPC is defined as occurring within the first 24 postnatal hours [3, 6]. Both these national surveys report an incidence of about 3 cases $/ 100,000$ infants (2.6 and 3.5/100,000, respectively). Notably, the German study excluded SUPC where an explanation could be found, while the English study included these, possibly preventable, SUPC cases in its report [3, 6]. However, recent guidelines for investigations of SUPC include infants with sudden unexpected collapse during the first postnatal week [7]. Moreover, in the reports that include also infants of postnatal age $<3$ or $<7$ days, roughly half of SUPC cases that are reported occur after $24 \mathrm{~h}$ (Table 3 ). Thus, excluding SUPC cases that occur after $24 \mathrm{~h}$ in reports will underestimate the incidence of sudden unexpected postnatal collapses in presumably healthy babies.

In addition, several clusters of cases have been described $[4,21,23]$. Most publications and authors indicate that the 
Table 3 Reported postnatal age of sudden unexpected postnatal collapse (SUPC)

\begin{tabular}{|c|c|c|c|c|c|c|}
\hline Reference & Number of infants & Included PN age & $<2 \mathrm{~h}$ & $2-24 \mathrm{~h}$ & $24-72 \mathrm{~h}$ & 4-7 days \\
\hline Polberger and Svenningsen [5] & $13^{\mathrm{b}}$ & $6-100 \mathrm{~h}$ & NA & 1 & 9 & 3 \\
\hline Burchfield and Rawlings [46] & 10 & $15-86 \mathrm{~h}$ & NA & 4 & 6 & 1 \\
\hline Dehan et al. [10] & 31 & $\leq 7$ days & 1 & 14 & 11 & 5 \\
\hline Rodriguez-Alarcon et al. [21] & 29 & $\leq 72 \mathrm{~h}$ & 9 & 8 & 12 & NA \\
\hline Grylack and Williams [18] & 20 & $\leq 72 \mathrm{~h}$ & 0 & 10 & 10 & NA \\
\hline Obonai et al. [27] & $9^{c}$ & $\leq 10$ days & 0 & 3 & 5 & 1 \\
\hline Kuhn et al. [38] & 2 & $\leq 2 \mathrm{~h}$ & 2 & NA & NA & NA \\
\hline Gatti et al. [16] & 6 & $\leq 2 \mathrm{~h}$ & 6 & 0 & NA & NA \\
\hline Espagne et al. [15] & 2 & $\leq 2 \mathrm{~h}$ & 2 & NA & NA & NA \\
\hline Inwald et al. [45] & 3 & $\leq 7$ days & 0 & 0 & 0 & 3 \\
\hline Toker-Maimon et al. [47] & 2 & $\leq 2 \mathrm{~h}$ & 2 & NA & NA & NA \\
\hline Aboudiab et al. [48] & 2 & $\leq 2 \mathrm{~h}$ & 2 & NA & NA & NA \\
\hline Branger et al. [49] & 11 & $\leq 7$ days & 4 & 4 & 1 & 1 \\
\hline Foran et al. [22] & 12 & $\leq 3$ days & 7 & 4 & 1 & $\mathrm{~N} A$ \\
\hline Dageville et al. [17] & 2 & $\leq 2 \mathrm{~h}$ & 2 & NA & NA & NA \\
\hline Nakamura and Sano [50] & 1 & $\leq 2 \mathrm{~h}$ & 1 & NA & NA & NA \\
\hline Peters et al. [4] & 5 & $\leq 12 \mathrm{~h}$ & 3 & 2 & NA & NA \\
\hline Schrewe et al. [51] & 1 & $\leq 2 \mathrm{~h}$ & 1 & NA & NA & NA \\
\hline Rodriguez-Alarcon et al. [23] & 5 & $\leq 2 \mathrm{~h}$ & 5 & NA & NA & NA \\
\hline Rodriguez-Alarcon et al. [23] & 8 & $\leq 2 \mathrm{~h}$ & 8 & NA & NA & NA \\
\hline Andres et al. [2] & 6 & $\leq 2 \mathrm{~h}$ & 6 & NA & NA & NA \\
\hline Poets et al. [3] & 17 & $\leq 24 \mathrm{~h}$ & 9 & 8 & NA & NA \\
\hline Leow and Platt [11] & 30 & $\leq 7$ days & 3 & 4 & 10 & 13 \\
\hline Becher et al. [6] & 45 & $\leq 12 \mathrm{~h}$ & 29 & 16 & NA & NA \\
\hline Tsao et al. [19] & 17 & $\leq 7$ days & 1 & 7 & 8 & 1 \\
\hline Poets et al. ${ }^{a}[12]$ & 17 & $\leq 24 \mathrm{~h}$ & 17 & NA & NA & \\
\hline Total & 306 & $0-7$ days & 103 & 85 & 73 & 28 \\
\hline Percentage of reported cases & & & $36 \%$ & $29 \%$ & $24 \%$ & $9 \%$ \\
\hline
\end{tabular}

Note that only 11 and 8 out of 26 studies provide data for events beyond 24 and $72 \mathrm{~h}$, respectively. The 11 studies that include SUPC events $<72 \mathrm{~h}$ report 73 cases out of 157 cases that occur between 24 and $72 \mathrm{~h}$

$P N$ postnatal, $N A$ not applicable

${ }^{\mathrm{a}}$ Inclusion only of the cases not published in Poets et al. [3]

${ }^{\mathrm{b}}$ only partial data coming from one substudy where postnatal age at event were described.

${ }^{\mathrm{c}}$ Excluding 1 SUDI case at 10 days.

number of reported SUPC cases is lower than what occurs in the wards and only reflects the most critical events [3]. Events with rapid and favorable outcome could easily be missed in large surveys [2]. One recent retrospective study indicates that the prevalence of early SUDI has not changed in northwest England during 35 years and is considered rare (3.5 SUDI/100,000) [11]. In contrast to the UK survey and report, Rodriguez-Alarcon et al. [23], in their regional study, show a significant increase in SUPC (ALTE as well as SUDI) since December 2008. They associate the increased SUPC incidence with altered routines in maternity wards and encouragement of early skin-to-skin contact but without adequate surveillance.
We have, in a separate report, investigated the prevalence of SUPC in three Stockholm University Hospitals examining some 68,000 births during 2.5 years, between January 2010 and July 2012. In this regional cohort study, the SUPC incidence is about half of the recent Spanish report but, nonetheless, nearly tenfold higher than in the UK and German national surveys (Pejovic and Herlenius, unpublished results). SUPC were vigorous stimulation enabled recovery are included in reports by Andres et al. (2 of 6 infants) [2] and Grylack et al. (20 infants) [18], but these cases are only mentioned in other studies and not included in some calculations of SUPC incidence, i.e., Poets et al. [12]. 
A consensus for coding unexpected postnatal collapse in ICD 10 has not yet been established. We think that also the early apparent life-threatening events occurring in newborn where vigorous stimulation, with or without positive pressure ventilation, should be included in the SUPC definition [7], as our cases 2 and 3 illustrate. If these, and other, unexpected collapses leading to sudden cyanotic infants had been discovered later, the consequences could have been more serious. These infants often need additional surveillance after resuscitation. Moreover, surviving cases outside of the hospital would have been classified as ALTE, and all SUPC cases should undergo structured investigations for possible preventable causes of the collapse [7]. In our case 3, a combination of underlying, possible causative factors, associated to the SUPC event, were found (PFO, PDA, TTN, and immature cardiorespiratory control). This allowed adequate therapeutic interventions, surveillance, and follow-up with good outcome.

Our summary of published reports indicates that even if still rare and with varying reported incidences, SUPC might occur more frequently than indicated in recent surveys. Even the lowest incidence numbers, if extrapolated on the 5 million annual births in the European Union, would result in some 500 SUPC cases and 150 newborn unexpected deaths yearly. Most of them are likely preventable.

\section{Known and Preventable Etiologies to SUPC}

Weber et al., in their review of autopsies performed over a 10year period, revealed an underlying cause of the SUPC leading to early SUDI in $58 \%$ of the 55 infants examined. All were born after gestational week 35 and died unexpectedly during the first postnatal week. Congenital heart malformations $(n=11)$ and infections $(n=9)$ were the leading causes of events, leading to sudden unexpected deaths, both potentially preventable with an early discovery (Tables 1 and 4). Sudden and unexpected death can occur in newborns with metabolic fatty organic acid (FAO) disorders [25]. A significant proportion of patients with an FAO disorder experience hypoglycemia within the first $72 \mathrm{~h}$ after birth and exhibit warning signals before a potential collapse [26]. Nonetheless, some of the SUDI described $(n=10)$ were due to metabolic disorders (Tables 1, 2, and 4) [6]. Most of the known disorders that are involved in the explained SUPC cases induce signs and warning signals in the infants before the collapse (Table 4). These collapses could be prevented with adequate surveillance and therapeutic support.

Birth and Attenuation of Brainstem Cardiorespiratory Control

Even if several of the unexpected deaths can be explained after autopsy [1], 153 described SUPC cases leading to
Table 4 Potentially preventable SUPC etiologies

\begin{tabular}{lll}
\hline Etiology to SUPC event & $N$ & Reference \\
\hline Infection & 26 & {$[5,6,10,12,15,19,45]$} \\
Cardiac disorder & 18 & {$[5,6,10,19]$} \\
PPHN respiratory disorder & 14 & {$[6,10,12,22]$} \\
Metabolic defects & 10 & {$[1,6,11,19]$} \\
Anemia & 3 & {$[5,6]$} \\
\hline
\end{tabular}

death remain unexplained (Tables 1 and 2) and have been classified as early SIDS. The present case 1 had a metabolic acidosis at birth, but recovered rapidly, and was presumed to be healthy before unexpectedly collapsing without an etiology was found in spite of extensive, clinical laboratory, and autopsy investigations.

A mild gliosis in brainstem areas involved in cardiorespiratory control was found in seven of nine cases reexamined by Obonai et al. [27]. They suggest that impaired cardiorespiratory control due to hypoxic ischemic insults occurring several days before death could contribute to these SUPC cases. A white matter gliosis was also found in 10 out of 16 unexplained SUDI cases, occurring mostly between days 8 and 28 of life [14]. However, these authors hypothesized that these lesions suggest that these infants could have experienced a previous prenatal or early postnatal central nervous system insult, thus making them vulnerable for known SIDS risk factors such as bed sharing. Our case 3 had an immature cardiorespiratory control and persistent pulmonary hypertension of the newborn. A planned cesarean section, before onset of spontaneous delivery, will lack the catecholamine surge induced by normal delivery and increase respiratory morbidity (odds ratios 2-4) [28]. The immature cardiorespiratory control, exemplified in our case 3, is in accordance with this as well as previous report where about half of the early ALTE cases examined had apneas $>15 \mathrm{~s}$ and desaturations $<85 \%$ with four infants exhibiting bradycardias (heart rate $<80$ beats/min for more than $5 \mathrm{~s}$ ) implying immature cardiorespiratory control [18]. We speculate that dysfunctional or immature brainstem cardiorespiratory control is involved in some of the unexplained SUPC cases.

The transition from fetal to extra-uterine life could make the newborn more vulnerable during the first hours of life. Before birth, the fetal brain microenvironment contains high levels of the neuromodulators adenosine and prostaglandin that both exert inhibition of the fetal movements, decrease metabolic rate, energy turnover, and thus protect the brain when oxygen and energy resources might be scarce, i.e., during birth. In fact, birth is a "hypoxic" and stressful event [29].

The healthy newborn baby is aroused and awake the first hour after birth and starts continuous breathing movements after the first gasps of air. Factors like squeezing and squashing 
of the fetus, increased sensory input, and cooling are important. There is also a noradrenaline surge in the human brain, and high level of plasma catecholamines is detected after birth [29]. Moreover, a rapid decrease in the inhibitory neuromodulator adenosine in the brain occurs, as partial pressure of oxygen in arterial blood rapidly increases after birth, and contributes to the increased activity in the newborn infant compared with the fetus [30]. The initial arousal of the newborn is followed by a period of diminished responsiveness to external stimuli [31] and increased vagal tone [32].

At birth, high levels of $\mathrm{PGE}_{2}$ are present in human term infants and neonates [33]. This is especially true during third stage of labor [34]. Hypoxia, per se, rapidly induces an increase in microsomal prostaglandin E synthase-1 activity and a subsequent brainstem-specific release of $\mathrm{PGE}_{2}$ with a depression of brainstem respiratory centers, e.g., see Fig. $1 \mathrm{~b}$ in Hofstetter et al. [35]. This is consistent with evidence that anoxia induces $\mathrm{PGE}_{2}$ production in mice cortex and prostaglandin $\mathrm{H}$ synthase-2 messenger RNA expression in the piglet brain [36]. $\mathrm{PGE}_{2}$ is thus involved in the acute hypoxic response, also recently shown by us [35, 37]. Actually, PGE levels in plasma are 20-fold higher in newborns than in 5-8week-old infants and declines rapidly during the first postnatal week [33]. Moreover, elevated levels of prostaglandin in the cerebrospinal fluid are present during the first $24 \mathrm{~h}$ after birth especially after birth asphyxia (Björk, Leifsdottir, Saha, and Herlenius, unpublished results). Presently, we can only speculate if these elevated levels of prostaglandin contribute to the postnatal irresponsiveness that begins some hour after birth and contribute to the SUPC occurring within the first hours after birth. This is a testable hypothesis, and we are currently examining the role of eicosanoids in autonomic control and SUPC during the first days of postnatal life [30].

\section{Well-Identified Risk Factors for SUPC}

A majority of events occur within $2 \mathrm{~h}$ of birth, often at the time of the first breastfeeding attempt $[6,12]$ (Table 3). Moreover, most of cases reported, where information is available, occur in prone position, i.e., [21, 23, 38], during skin-to-skin contact with their mothers (Table 1). In fact, SUPC is associated with prone position/skin-to-skin/ cobedding in $74 \%$ (152 out of 207 cases; Tables 1 and 2). This in agreement with Poets et al. who, based on their 31 cases and 93 "controls," estimated an odds ratio of 6.4 for SUPC to occur in prone or "potentially asphyxiating position" when an identified cause could not be identified [12]. Moreover, SUDI occurring in the first month of life is associated with bed sharing [14].

All the present three cases occurred in newborns to primiparous mothers during skin-to-skin contact, which is consistent with previous reports. Prone position, first breastfeeding attempt, cobedding, mother in episiotomy position, a primiparous mother, and parents left alone with baby during first hours after birth have been identified as risk factors for SUPC or early SIDS in several recent publications $[2,4,12,17,24,39,40]$.

\section{SUPC-SIDS Analogous Mechanisms and Risk Factors?}

The current concept of SIDS is based on the "triplerisk" hypothesis of an underlying genetic or developmental predisposition in combination with an external trigger acting synergistically at a vulnerable developmental period [41]. Nevertheless, despite recognition of possible generic mechanisms and epidemiological risk factors, the exact mechanism(s) of death is still unclear. The occurrence of an alveolar septal collapse in the neonatal lung has been shown to induce severe hypoxemia and to be involved in some early SUDI cases [42]. This possible biomechanical mechanism has been hypothesized to explain the association of the known risk factors for SUDI such as cosleeping, prematurity, prone sleeping position, overwrapping, overheating, and maternal smoking and possibly also be involved in some SUPC events.

Although deaths in the first week of life are often not included in SIDS datasets, the current and other summaries of SUPC cases and risk factors $[1,12]$ suggest that similar processes to SIDS may account for about half of all sudden unexpected deaths of apparently previously healthy infants in the first week of life [1]. In ALTE, the role of central respiratory control immaturity is established, and the same risk factors as for SIDS are apparent, at least during the first $24 \mathrm{~h}$ of life [43].

Recommendations that all newborn infants should be placed in supine position within the first few hours after birth are emphasized in the reports of SUPC and in the guidelines to reduce the risk of SIDS [44].

\section{Recommendations to Promote and Implement to Reduce} SUPC

Different preventive measures and organizations of care have been strongly recommended by the majority of authors. Regardless of SUPC's etiology, the most important point underlined by most authors as well as in the current report is to maintain unobtrusively, but continuously, a secure surveillance of the newborn during his first hours and days of life. Barriers to this during night/weekend times or periods of overwork in busy units should not be disregarded and should be taken into account using quality process audit in each center. The three targets on which perinatal healthcare teams could focus to protect otherwise 
healthy newborns, are (1) safe early skin-to-skin care (SSC) in the delivery room, (2) safe breastfeeding establishment in the first days of life, and (3) secure positioning of the infant during sleep. Some tools to reach them are summarized in Box 1.

- Systematic information of the parents about signs of infant's well-being and the need to maintain an adequate supervision ensuring upper airway patency of the newborn infant.

- Parental education to use the recommended supine position and to avoid, already from first hours of life, recognized risk factors for SIDS (co-bedding or bed-sharing, prone sleeping in soft bedding, face down and head covering) $(43,44)$

- Appropriate non-obtrusive surveillance of the newborn's clinical condition by caregivers aware of the possibility of SUPC and continuous clinical supervision of mothers at risk (primiparous, alone and exhausted).

- Medical supervision to discuss the opportunity of SSC, in case of pathological conditions of the mother (sedative treatment, infection) or the newborn (difficult adaptation, mild respiratory distress, suspicion of infection).

- Position the infant supine to avoid mechanical airway obstruction or a possibly asphyxiating position[44].

\section{Risk Reduction Strategies to Prevent Sudden Unexpected Postnatal Collapses}

The impact of the implementation of these recommendations should be evaluated, and they could also help prevent further cases occurring in otherwise healthy infants. Moreover, the early recognition of an underlying disease could allow therapeutic intervention and improvement of longterm outcome.

Even if SUPC is a rare entity, an adequate surveillance of the infants, during their first hours (and days) of life, should enable us to save hundreds of newborn lives annually.

\footnotetext{
Acknowledgments The Swedish Research Council, the Stockholm County Council, and Karolinska Institutet, supported this work as well as a mobility grant from the "Association de Néonatologie de Port Royal" (Paris, France) to Pierre Kuhn. We thank the physicians and midwives that reported these cases. We are indebted to Drs. Nicolas Pejovic, Hugo Lagercrantz, Giovanna Marchini, Veronica Siljehav, Monica Perez, and Gary Cohen for valuable discussions, helpful suggestions, and native language assistance.
}

Conflict of interest The authors declare that they have no conflict of interest.

Open Access This article is distributed under the terms of the Creative Commons Attribution License which permits any use, distribution, and reproduction in any medium, provided the original author(s) and the source are credited.

\section{References}

1. Weber MA, Ashworth MT, Risdon RA, Brooke I, Malone M, Sebire NJ. Sudden unexpected neonatal death in the first week of life: autopsy findings from a specialist centre. J Matern Fetal Neonatal Med. 2009;22:398-404.

2. Andres V, Garcia P, Rimet Y, Nicaise C, Simeoni U. Apparent life-threatening events in presumably healthy newborns during early skin-to-skin contact. Pediatrics. 2011;127:e1073-6.

3. Poets A, Steinfeldt R, Poets CF. Sudden deaths and severe apparent life-threatening events in term infants within $24 \mathrm{~h}$ of birth. Pediatrics. 2011;127:e869-73.

4. Peters C, Becher JC, Lyon AJ, Midgley PC. Who is blaming the baby? Arch Dis Child Fetal Neonatal Ed. 2009;94:F377-8. 
5. Polberger S, Svenningsen NW. Early neonatal sudden infant death and near death of fullterm infants in maternity wards. Acta Paediatr Scand. 1985;74:861-6.

6. Becher JC, Bhushan SS, Lyon AJ. Unexpected collapse in apparently healthy newborns - A prospective national study of a missing cohort of neonatal deaths and near-death events. Arch Dis Child Fetal Neonatal Ed. 2012;97:F30-4.

7. Wellchild. Guidelines for the investigation of newborn infants who suffer a sudden and unexpected postnatal collapse in the first week of life: recommendations from a Professional Group on Sudden Unexpected Postnatal Collapse. London; 2011.

8. Liberati A, Altman DG, Tetzlaff J, Mulrow C, Gotzsche PC, Ioannidis JP, et al. The PRISMA statement for reporting systematic reviews and meta-analyses of studies that evaluate health care interventions: explanation and elaboration. PLoS medicine. 2009;6:e1000100.

9. Stroup DF, Berlin JA, Morton SC, Olkin I, Williamson GD, Rennie D, et al. Meta-analysis of observational studies in epidemiology: a proposal for reporting. Meta-analysis of Observational Studies in Epidemiology (MOOSE) group. JAMA: J Am Med Assoc. 2000;283:2008-12.

10. Dehan M, Imbert MC, Benisvy C, Roset F, Gautier JP, Magny JF. et al [Sudden newborn infant death in maternity. Anatomo-clinical study of 31 cases]. Arch Fr de Pediatr. 1992;49:609-16.

11. Leow JY, Platt MP. Sudden, unexpected and unexplained early neonatal deaths in the North of England. Arch Dis child Fetal Neonatal Ed. 2011;96:F440-2.

12. Poets A, Urschitz MS, Steinfeldt R, Poets CF. Risk factors for early sudden deaths and severe apparent life-threatening events. Arch Dis Child Fetal Neonatal Ed 2012;97:F395-7

13. Ottaviani G, Lavezzi AM, Matturri L. Fibromuscular hyperplasia of the pulmonary artery in sudden infant and perinatal unexpected death. Cardiovasc Pathol: Off J Soc Cardiovasc Pathol. 2009; 18:223-30.

14. Chiu M, Elder D, Zuccollo J. Gliosis in neonatal SUDI cases. Acta Paediatr. 2012;101:30-3.

15. Espagne S, Hamon I, Thiebaugeorges O, Hascoet JM. [Sudden death of neonates in the delivery room]. Arch de Pediatr: Organe Off de la Societe Fr de pediatr. 2004;11:436-9.

16. Gatti H, Castel C, Andrini P, Durand P, Carlus C, Chabernaud JL. et al [Cardiorespiratory arrest in full term newborn infants: Six case reports]. Arch de Pediatr: Organe Off de la Societe Fr de pediatr. 2004;11:432-5.

17. Dageville C, Pignol J, De Smet S. Very early neonatal apparent life-threatening events and sudden unexpected deaths: incidence and risk factors. Acta Paediatr. 2008;97:866-9.

18. Grylack LJ, Williams AD. Apparent life-threatening events in presumed healthy neonates during the first three days of life. Pediatrics. 1996;97:349-51.

19. Tsao PC, Chang FY, Chen SJ, Soong WJ, Jeng MJ, Lee YS, et al. Sudden and unexpected and near death during the early neonatal period: a multicenter study. J Chin Med Assoc: JCMA. 2012;75:65-9.

20. Cohen G, Vella S, Jeffery H, Lagercrantz H, Katz-Salamon M. Cardiovascular stress hyperreactivity in babies of smokers and in babies born preterm. Circulation. 2008;118:1848-53.

21. Rodriguez-Alarcon J, Melchor JC, Linares A, Aranguren G, Quintanilla M, Fernandez-Llebrez L, et al. Early neonatal sudden death or near death syndrome. An epidemiological study of 29 cases. Acta Paediatr. 1994;83:704-8.

22. Foran A, Cinnante C, Groves A, Azzopardi DV, Rutherford MA, Cowan FM. Patterns of brain injury and outcome in term neonates presenting with postnatal collapse. Arch Dis Child Fetal Neonatal Ed. 2009;94:F168-77.

23. Rodriguez-Alarcon J, Melchor JC, Fernandez-Llebrez L, Uria C. Episodios aparentemente letales en las primeras dos horas de vida durante el contacto piel con piel. Incidencia y factores de riesgo-Apparently life-threatening episodes in the first two hours of life during skin-to-skin mother-infant contact. Incidence and risk factors. Progresos de Obsterica Y Ginecologi. 2011;54:559.

24. Hays S, Feit P, Barre P, Cottin X, Huin N, Fichtner C, et al. [Respiratory arrest in the delivery room while lying in the prone position on the mothers' chest in 11 full term healthy neonates]. Arch de Pediatr: Organe Off de la Societe Fr de pediatr. 2006;13:1067-8.

25. Bennett MJ, Powell S. Metabolic disease and sudden, unexpected death in infancy. Hum Pathol. 1994;25:742-6.

26. Rinaldo P, Yoon HR, Yu C, Raymond K, Tiozzo C, Giordano G. Sudden and unexpected neonatal death: a protocol for the postmortem diagnosis of fatty acid oxidation disorders. Semin Perinatol. 1999;23:204-10.

27. Obonai T, Asanuma M, Mizuta R, Horie H, Tanaka J, Takashima $\mathrm{S}$. Evidence of brain ischemia in early neonatal sudden death syndrome. Neuropediatrics. 1997;28:145-8.

28. Ramachandrappa A, Jain L. Elective cesarean section: its impact on neonatal respiratory outcome. Clin Perinatol. 2008;35:373-93. vii.

29. Herlenius E, Lagercrantz H. Neurotransmitters and neuromodulators during early human development. Early Hum Dev. 2001;65:21-37.

30. Herlenius E. An inflammatory pathway to apnea and autonomic dysregulation. Respir Physiol Neurobiol. 2011;178:449-57.

31. Cohen G, Katz-Salamon M, Malcolm G. A key circulatory defence against asphyxia in infancy - the heart of the matter! J Physiol. 2012;590:6157-65.

32. Cordero Jr L, Hon EH. Neonatal bradycardia following nasopharyngeal stimulation. J Pediatr. 1971;78:441-7.

33. Mitchell MD, Lucas A, Etches PC, Brunt JD, Turnbull AC. Plasma prostaglandin levels during early neonatal life following term and pre-term delivery. Prostaglandins. 1978;16:319-26.

34. Sellers SM, Hodgson HT, Mitchell MD, Anderson AB, Turnbull AC. Raised prostaglandin levels in the third stage of labor. Am J Obstet Gynecol. 1982;144:209-12.

35. Hofstetter AO, Saha S, Siljehav V, Jakobsson PJ, Herlenius E. The induced prostaglandin E2 pathway is a key regulator of the respiratory response to infection and hypoxia in neonates. Proc Natl Acad Sci U S A. 2007;104:9894-9.

36. Degi R, Bari F, Thrikawala N, Beasley TC, Thore C, Louis $\mathrm{TM}$, et al. Effects of anoxic stress on prostaglandin $\mathrm{H}$ synthase isoforms in piglet brain. Brain Res Dev Brain Res. 1998;107:265-76.

37. Siljehav V, Olsson Hofstetter A, Jakobsson PJ, Herlenius E. mPGES-1 and prostaglandin E(2): vital role in inflammation, hypoxic response, and survival. Pediatr Res. 2012;72:460-7.

38. Kuhn P, Donato L, Laugel V, Beladdale J, Escande B, Matis J, et al. Malaise grave précoce du nouveau-né: A propos de deux cas survenus en salle de naissance. J Gynecol Obstet Biol Reprod. 2001;30:92-3.

39. Becher J-C, Bhushan SS, Lyon AJ. Unexpected collapse in apparently healthy newborns - a prospective national study of a missing cohort of neonatal deaths and near-death events. Arch Dis Child Fetal Neonatal Edition. 2012;97:F30-F4.

40. Fleming PJ. Unexpected collapse of apparently healthy newborn infants: the benefits and potential risks of skin-to-skin contact. Arch Dis Child Fetal Neonatal Ed. 2012;97:F2-3.

41. Mitchell EA. SIDS: past, present and future. Acta Paediatr. 2009;98:1712-9.

42. Sebire NJ, Talbert D. Alveolar septal collapse in the transitional infant lung: a possible common mechanism in sudden unexpected death in infancy. Med Hypotheses. 2004;63:485-93.

43. Fu LY, Moon RY. Apparent life-threatening events: an update. Pediatr Rev Am Acad Pediatr. 2012;33:361-8. quiz 8-9. 
44. Moon RY. SIDS and other sleep-related infant deaths: expansion of recommendations for a safe infant sleeping environment. Pediatrics. 2011;128:1030-9.

45. Inwald D, Franklin O, Cubitt D, Peters M, Goldman A, Burch M. Enterovirus myocarditis as a cause of neonatal collapse. Arch Dis Child Fetal Neonatal Ed. 2004;89:F461-2.

46. Burchfield DJ, Rawlings DJ. Sudden deaths and apparent lifethreatening events in hospitalized neonates presumed to be healthy. Am J Dis Child. 1991;145:1319-22.

47. Toker-Maimon O, Joseph LJ, Bromiker R, Schimmel MS. Neonatal cardiopulmonary arrest in the delivery room. Pediatrics. 2006;118:847-8.
48. Aboudiab T, Vue-Droy L, Al Hawari S, Attier S, Chouraki JP. [Is there a risk with the skin-to-skin practice at birth?]. Arch de Pediatr: Organe Of de la Societe Francaise de Pediatr. 2007;14:1368-9.

49. Branger B, Savagner C, Roze JC, Winer N. [Eleven cases of early neonatal sudden death ou near death of full term and healthy neonates in maternity wards]. Jde Gynecol Obstet Biol Reprod. 2007;36:671-9.

50. Nakamura T, Sano Y. Two cases of infants who needed cardiopulmonary resuscitation during early skin-to-skin contact with mother. J Obstet Gynaecol Res. 2008;34:603-4.

51. Schrewe B, Janvier A, Barrington K. Life-threatening event during skin-to-skin contact in the delivery room. BMJ case reports. 2010; 2010 . 